\title{
Autoimmune progesterone dermatitis: Case report with history of urticaria, petechiae and palpable pinpoint purpura triggered by medical abortion
}

\author{
L Mbonile, MB ChB, MPH, Pg Dipl (HIV/AIDS Management) \\ Anatomy and Histopathology, Medical Biosciences Department, University of the Western Cape, Cape Town, and Mbeya Referral Hospital, \\ Ministry of Health and Social Welfare, Mbeya, Tanzania
}

Corresponding author: L Mbonile(lmbonile@uwc.ac.za)

\begin{abstract}
Autoimmune progesterone dermatitis (APD) is a rare autoimmune response to raised endogenous progesterone levels that occur during the luteal phase of the menstrual cycle. Cutaneous, mucosal lesions and other systemic manifestations develop cyclically during the luteal phase of the menstrual cycle when progesterone levels are elevated. APD symptoms usually start 3 - 10 days before menstruation and resolve $1-2$ days after menstruation ceases. A 30-year-old woman presented with urticaria, petechiae and palpable pinpoint purpura lesions of the legs, forearms, neck and buttocks 1 week prior to her menses starting and 2 months after a medical abortion. She was diagnosed with allergic contact dermatitis and topical steroids were prescribed. Her skin conditions did not improve and were associated with her menstrual cycle. We performed an intradermal test using progesterone, which was positive. She was treated with oral contraceptive pills and the symptoms were resolved. This is a typical case of APD triggered by increased sensitivity to endogenous progesterone induced a few months after medical abortion.
\end{abstract}

S Afr Med J 2016;106(4):356-358.DOI:10.7196/SAMJ.2016.v106i4.9896

Autoimmune progesterone dermatitis (APD) is a rare condition, characterised by recurrent premenstrual cyclic eruptions. ${ }^{[1]}$ It may present with a variety of cutaneous and mucosal manifestations but urticaria, erythema multiforme, eczematous, and vesicular or papulovesicular eruptions are the most common. APD is considered to be a hypersensitivity reaction to an increased level of endogenous progesterone during the luteal phase of the menstrual cycle. Exposure to exogenous progesterone plays a big role in the pathogenesis of APD. APD was first reported by Gerber $^{[1]}$ in $1921 .{ }^{[2,3]}$

\section{Case report}

A 30-year-old black, uniparous woman with no significant past dermatological history and no prior exogenous hormone presented at the clinic complaining of persistent cyclic skin eruptions and urticaria of over 2 months. She reported that symptoms started immediately before getting her normal menstrual cycle after medical abortion. She noted that the pruritic skin lesions were exacerbated 4 - 5 days before the onset of her menses, lasted for $\sim 5$ days, and partially improved within 1 - 2 days after the end of the menses. There was no complete clearance of the lesions between menstrual cycles. When she first reported the symptoms to her GP, the initial diagnosis was allergic contact dermatitis and topical steroids were prescribed but only slight improvement was shown.
Clinical examination revealed urticaria, petechiae and palpable pinpoint purpura lesions, distributed over the legs, forearms, neck and buttocks (Fig. 1, A - D). The presumptive diagnosis of autoimmune progesterone dermatitis was made. An intradermal skin test using $0.1 \mathrm{cc}$ of progesterone was performed. The patient immediately deve-

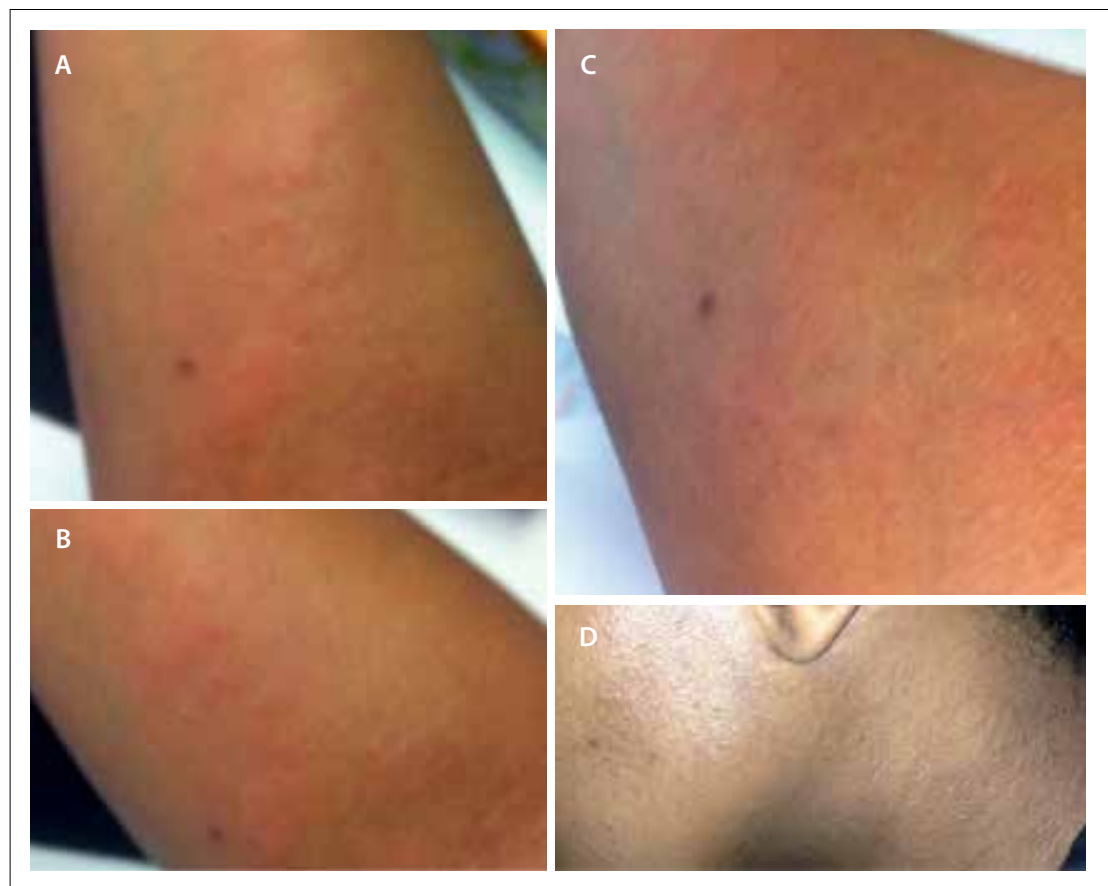

Fig. 1. Autoimmune progesterone dermatitis. Pruritic, erythematous, and urticarial papules on (A) left

forearm; (B) right forearm; (C) left leg; and (D) left side of the neck and face.

loped a wheal, confirming the diagnosis of APD. She was reluctant to have a skin biopsy. No abnormal values were found in the routine blood chemistry and hormonal examinations.

A continuous regimen of an oral contraceptive pill with $30 \mathrm{mg}$ ethinyl oestradiol and $0.15 \mathrm{mg}$ of levonorgestrel was started on the 
patient. The skin eruptions have not returned since the initiation of this therapy.

The medical report request was sent to her first GP and he confirmed that the medical abortion was induced using mifepristone $600 \mathrm{mg}$ with tabs misoprostol (400 mg start then $200 \mathrm{mg}$ three times a day for 4 days). Routine serum $\beta$ hCG tests, antibiotics and anti-pain medications were also prescribed.

APD manifests via the occurrence of cyclic skin eruptions. Women with the disorder commonly present with dermatological lesions in the luteal phase of the menstrual cycle. ${ }^{[4,5]}$ Diagnosis of APD is confirmed by performing a skin allergen test using progesterone ${ }^{\left[{ }^{[5]}\right.}$ Due to its rarity, APD should be considered a diagnosis of exclusion. ${ }^{[6-9]}$ In this case, we believe symptoms occurred as a result of increased hypersensitivity to endogenous progesterone, triggered immediately after medical abortion.

\section{Discussion}

Hormones of the anterior pituitary gland are relatively inactive prior to puberty. They are usually released $2-3$ years prior to puberty after the initial release of gonadotropin-releasing hormone $(\mathrm{GnRH})$ by the hypothalamus. ${ }^{[10]}$ It is still uncertain what triggers this sudden increase in GnRH a few years after puberty. GnRH is released in a rhythmic, pulsatile manner resulting in the pulsatile release of luteinising hormone (LH) and follicle-stimulating hormone (FSH) by the anterior pituitary gland..$^{[10-12]}$ The primary function of FSH is to stimulate the granulosa cells of the ovary to synthesise oestrogen ${ }^{[12]}$ For transformation of the oestrogen-secreting stromal cells of the ovary to progestogen-secreting cells, LH is needed. Apart from the stimulation of progesterone production, $\mathrm{LH}$ is essential for final oocyte maturation and the trigger of ovulation. ${ }^{[10]}$

Progesterone is secreted by the ovary mainly from the corpus luteum during the second half of the menstrual cycle. ${ }^{[11]}$ Secretion actually begins just before ovulation from the follicle that is destined to release an ovum. Progesterone, like all other steroid hormones, is synthesised from pregnenolone, which in turn is derived from cholesterol. It occurs in the ovary, testes, adrenal cortex and placenta. ${ }^{[10,11]}$ The stimulatory effect of $\mathrm{LH}$ on progesterone synthesis and secretion by the corpus luteum is mediated by a membrane-bound receptor linked to a G-protein-coupled signal transduction pathway that increases the synthesis of cyclic adenosine monophosphate (AMP) by the stimulation of adenylyl cyclase. ${ }^{[13]}$ If the ovum is fertilised, implantation takes place about 7 days later, and almost at once the developing trophoblast begins secreting human chorionic gonadotropin (hCG) into the maternal circulation, thereby sustaining the functional life of the corpus luteum. During the second or third month of pregnancy, the developing placenta begins to secrete oestrogen and progesterone in collaboration with fetal adrenal glands, and thereafter the corpus luteum is not essential to continued gestation. Oestrogen and progesterone continue to be secreted in large amounts by the placenta up to the time of delivery. The rate of progesterone increases from a few mg per day secreted during the follicular phase of the cycle, to $10-20 \mathrm{mg}$ during the luteal phase and to several hundred mg during the latter part of pregnancy. ${ }^{[6,10-12]}$

APD is a rare disorder characterised by cyclic eruption of varying morphology and distribution..$^{[9,14-16]}$ The eruption is induced by hypersensitivity to endogenous progesterone, and typically occurs during the luteal phase of the menstrual cycle as serum levels of this hormone increase. Partial to complete resolution occurs within days of menstruation, with recurrence during the next menstrual cycle. The eruption may be localised or generalised. Sensitisation with exogenous oestrogen in oral contraceptives may be an inciting factor in some cases ${ }^{[8,9,17]}$ Pregnancy may either worsen or improve the condition. ${ }^{[6,9]}$ APD symptoms range from minor to severe skin
Table 1. Treatment options used in APD

\begin{tabular}{ll}
\hline Treatment & Advantage(s) \\
$\begin{array}{l}\text { Pharmacological } \\
\text { Antihistamines }\end{array}$ & $\begin{array}{l}\text { Usually tried as initial therapy } \\
\text { Fewer side-effects than most other } \\
\text { therapies } \\
\text { Well tolerated, few side-effects }\end{array}$ \\
Avoids progesterone component of \\
OCPs \\
Glucocorticoids & $\begin{array}{l}\text { Able to suppress multiple components } \\
\text { of the immune system } \\
\text { Can be combined with other therapies } \\
\text { Often used if OCPs and glucocorticoids } \\
\text { are not effective } \\
\text { Can be combined with low-dose steroids } \\
\text { Anterferes with gonadal hormone }\end{array}$ \\
Tamoxifen & $\begin{array}{l}\text { receptors } \\
\text { Has been used successfully in patients } \\
\text { unresponsive to conjugated oestrogen }\end{array}$ \\
Surgical & $\begin{array}{l}\text { Definitive treatment, used if medical } \\
\text { options unsuccessful }\end{array}$ \\
Bilateral oophorectomy & \\
OCPs = oral contraceptives. &
\end{tabular}

presentations to severe systemic complications such as symptoms of asthma or anaphylaxis ${ }^{[6,18-20]}$ Dermatological manifestations of APD include: urticaria, angio-oedema, eczema, erythema multiforme, stomatitis, folliculitis, papulopustular/papulovesicular lesions, Stephens-Johnson syndrome, vesiculobullous reactions, dermatitis herpetiformis-like rash and mucosal lesions.

The pathogenesis of APD is unknown. It is believed both endo- and exogenous progesterones at some stage stimulate immunoglobulin $\mathrm{E}$ (IgE) synthesis. This mechanism has still not been clearly investigated, especially on endogenous progesterone. ${ }^{[21-24]}$ Some authors have suggested that hydrocortisone or 17- $\alpha$-hydroxyprogesterone have cross-sensitivity with progesterone and may cause initial sensitisation, but this has not been observed in all studies. ${ }^{[6,9]}$ Some researchers have linked APD with specific antibodies, this having been established by using immunofluorescent techniques and basophil degranulation tests. Skin test results with progesterone have shown immediate reactions (within 30 minutes), delayed reactions (24 - 48 hours later) and reactions with both immediate and delayed features. ${ }^{[4,6,18,25]}$ This presumably indicates both type I and type IV hypersensitivity reactions. Progesterone has also been reported to have a direct histamine-releasing effect on mast cells and in one study found an in vitro increase of an interferon- $\gamma$ release assay, likely from TH1-type cytokines. Other researchers have correlated the presence of APD skin conditions with increased eosinophils levels. ${ }^{[4,6,18,25]}$

In this case the first clinicians failed to link the appearance of current symptoms with APD. This is very common to many patients with APD. The peculiarity of this case is on the timing, as the symptoms started immediately after the induction of medical abortion with mifepristone. Mifepristone (RU 486) is a derivative of the 19-norprogestin norethindrone containing a dimethyl-aminophenyl substituent at the $11 \beta$-position. ${ }^{[13,26]}$ It is a potent competitive antagonist of both progesterone and glucocorticoid, binding to their respective receptors. When administered in the early stages of pregnancy, 
mifepristone causes decidual breakdown by blocking the uterine progesterone receptors. This leads to the detachment of the blastocyst, which decreases HCG production. This in turn causes a decrease in progesterone secretion from the corpus luteum, which further accentuates decidual breakdown. Decreased endogenous progesterone coupled with the blockage of progesterone receptors in the uterus increases uterine prostaglandin levels and sensitises the myometrium to the contractile actions of prostaglandins. ${ }^{[26]}$ Mifepristone also affects ovulation. If given accurately in the mid- to late-follicular phase, it delays follicle maturation and the LH surge, and ovulation occurs later than normal. ${ }^{[13,26]}$

Blockage of progesterone receptors by the mifepristone triggers the decrease of progesterone levels in the body. One month after the abortion, the patient expected normal menstrual flow, but this did not happen. This might explain the further drop in oestrogen and progesterone levels or the decrease in sensitivity of the receptors after mifepristone blockage. This might have been taken as normal menstrual flow irregularity, but it explains the decrease from normal levels as a result of medical abortion. Most of the receptors in the body have a common characteristic of increasing or accelerating the action of the hormone or chemical immediately after the blockage or when the hormone levels increase above the normal level. ${ }^{[1,12]}$ Increased receptor sensitivity after blockage is very common. Sensitivity increase from endogenous progesterone after mifepristone blockage can also be due to a negative feedback mechanism as a result of the production of progesterone. With the decrease in the level of progesterone immediately after medical abortion, the hormonal control mechanism of the progesterone might have shifted and caused an abrupt increase in the production of the hormone at the corpus luteum and adrenal cortex, causing APD. This can be explained by the increase of sensitivity to progesterone confirmed by the skin allergen test. As explained above, the pathogenesis of APD is not clearly known, but in this case the increase in progesterone levels 1 month after medical abortion might have stimulated the IgE synthesis, hence causing both type I and type IV hypersensitivity reactions.

APD is usually resistant to conventional therapy such as antihistamines. ${ }^{[6]}$ The use of systemic glucocorticoids, usually in high doses, has been reported to control the cutaneous lesions of APD in some cases ${ }^{[4,6,18,25]}$ This patient was also treated with topical steroids prior to our confirmed diagnosis. Several treatment modalities have been used in the treatment of APD. The most used are the ones that attempt to inhibit the secretion of endogenous progesterone by the suppression of ovulation. ${ }^{[2,6]}$ Table 1 lists some of the pharmacological and surgical strategies used in APD management. OCPs are often tried as initial therapy, but have had limited success, possibly due to the fact that virtually all OCPs have a progesterone component. ${ }^{[6]}$ In this case, OCPs worked very well and there was no need to change the regimen. Some clinicians also reported using conjugated oestrogens. However, due to the increased risk of endometrial carcinoma with unopposed conjugated oestrogens, this treatment is not commonly used. ${ }^{[2,6,27]}$

GnRH agonists, such as buserelin and triptorelin, have been used to induce remission of symptoms by causing ovarian suppression. ${ }^{[6,28-30]}$ However, side-effects include symptoms of oestrogen deficiency (hot flushes, vaginal dryness and decreased bone mineral density) and oestrogen supplementation may be needed. ${ }^{[6,25]}$ Alkylated steroids such as stanozol have been used to successfully suppress ovulation, sometimes in combination with chronic low doses of corticosteroids. Side-effects of alkylated steroids include abnormal facial or body hair growth, hepatic dysfunction and mood disorders. ${ }^{[6]}$ Thorough evaluations should be made if these are given to a patient.
In many cases, anti-oestrogens have been used, most commonly tamoxifen, which can also suppress ovulation. ${ }^{[8,31]}$ Though reported to be used by many clinicians, tamoxifen has shown to be associated with symptoms of oestrogen deficiency and increased risk of venous thrombosis and cataract formation. Extra monitoring is important if it is given to patients with high risk. ${ }^{[6,8,31]}$ Surgery has been used in some severe cases of APD. This line of management is usually taken after medical options have failed. Bilateral oophorectomy is normally used to control severe forms of APD symptoms. ${ }^{[6,8,31]}$

\section{Conclusion}

This was a case of APD which was triggered by increased sensitivity of endogenous progesterone caused by medical abortion. A positive intradermal test with progesterone confirmed the diagnosis, and the response to oral contraceptives was prompt and dramatic. This is one of the rare cases of APD that was induced immediately after a successful medical abortion. Dermatol 1930;51(6):265-268.

2. George R, Badawy SZ. Autoimmune progesterone dermatitis: A case report. Case Rep Obstet Gynecol 2012;2012:757854. DOI:10.1155/2012/757854

Halevy S, Cohen AD, Lunenfeld E, Grossman N. Autoimmune progesterone dermatitis manifested as erythema annulare centrifugum: Confirmation of progesterone sensitivity by in vitro interferongamma release. J Am Acad Dermatol 2002;47(2):311-313. DOI:10.1186/1476-7961-2-10

4. Kakarla N, Zurawin RK. A case of autoimmune progesterone dermatitis in an adolescent female Kakarla N, Zurawin RK. A case of autoimmune progesterone dermatitis in
J Pediatr Adolesc Gynecol 2006;19(2):125-129. DOI:10.1016/.jpag.2006.01.050

J Pediatr Adolesc Gynecol 2006;19(2):125-129. DOI:10.1016/j.jpag.2006.01.050
5. Rasi A, Khatami A. Autoimmune progesterone dermatitis. Int J Dermatol 2004;43(8):588-590. Rasi A, Khatami A. Autoimmune pro
DOI:10.1111/j.1365-4632.2004.02155.x

DOI:10.1111/j.1365-4632.2004.02155.x Baptist AP, Baldwin JL. Autoimmune progesterone dermatitis in a patient with endometriosis:
report and review of the literature. Clin Mol Allergy 2004;2(1):10. DOI:10.1186/1476-7961-2-10

7. Bernstein IL, Bernstein DI, Lummus ZL, Bernstein JA. A case of progesterone-induced anaphylaxis, cyclic urticaria/angioedema, and autoimmune dermatitis. J Womens Health (Larchmt) 2011;20(4):643648. DOI:10.1089/jwh.2010.2468

8. Poffet F, Abraham S, Taramarcaz P, Fontao L, Borradori L. Autoimmune progesterone dermatitis: Potentia role of cutaneous angiogenin expression? Dermatology 2011;223(1):32-35. DOI:10.1159/000329427

9. Walling HW, Scupham RK. Autoimmune progesterone dermatitis. Case report with histologic overlap of erythema multiforme and urticaria. Int J Dermatol 2008;47(4):380-382. DOI:10.1111/j.1365-4632.2008.03395.x 0. Odendaal H. Physiology. In: Odendaal H, Schaetzing A, Kruger T, eds. Clinical Gynaecology. 2nd ed. Cape Town: Juta Academic, 2008:71-80.

11. Ganong WF, Barrett KE. Review of medical physiology. New York: McGraw-Hill Medical, 2005:415-457. 12. Hall JE. Guyton and Hall Textbook of Medical Physiology. 12th ed. Philadelphia: Saunders Elsevier 2011:1003-1015.

13. Williams C, Stan G. Estrogens and progestins. In: Joel Hardman LK, Perry Molinoff, Raymond Ruddon, Alfred Gilman, eds. Goodman and Gilman's The Pharmacological Basis of Therapeutics. 9th ed. New York: McGraw-Hill, 1996:1411-1437.

14. Prieto-Garcia A, Sloane DE, Gargiulo AR, Feldweg AM, Castells M. Autoimmune progesterone dermatitis: Clinical presentation and management with progesterone desensitization for successful in vitro fertilization. Fertil Steril 2011;95(3):9-13. DOI:10.1016/j.fertnstert.2010.10.038

15. Shelley WB, Shelley ED, Talanin NY, Santoso-Pham J. Estrogen dermatitis. J Am Acad Dermatol 1995;32(1):25-31. DOI:10.1016/0190-9622(95)90179-5

16. Stephens CJ. Perimenstrual eruptions. Clin Dermatol 1997;15(1):31-34. DOI:10.1016/S0738081X(96)00107-1

7. Pereira A, Coker A. Hypersensitivity to Mirena - a rare complication. J Obstet Gynaecol 2003;23(1):81.

8. Jenkins J, Geng A, Robinson-Bostom L. Autoimmune progesterone dermatitis associated with infertility treatment. J Am Acad Dermatol 2008;58(2):353-355. DOI:10.1016/j.jaad.2007.10.646 19. Le K, Wood G. A case of autoimmune progesterone dermatitis diagnosed by progesterone pessary
Australas I Dermatol 2011:52(2):139-141. DOI:10.1111/j.1440-0960.2011.00753.

20. McCalmont TH. Fact or fiction? J Cutan Pathol 2010;37(11):1130-1131. DOI:10.1111/j.16000560.2010.01616.x

21. Anderson RH. Autoimmune progesterone dermatitis. Cutis 1984;33(5):490-491.

21. Anderson RH. Autoimmune progesterone dermatitis. Cutis 1984;33(5):490-491.
22. Chawla SV, Quirk C, Sondheimer SJ, James WD. Autoimmune progesterone dermatitis. Arch Chawla SV, Quirk C, Sondheimer SJ, James WD. Autoimmune
Dermatol 2009;145(3):341-342. DOI: 10.1001/archdermatol.2008.605

23. Nasabzadeh TJ, Stefanato CM, Doole JE, Radfar A, Bhawan J, Venna S. Recurrent erythema multiforme triggered by progesterone sensitivity. J Cutan Pathol 2010;37(11):1164-1167. DOI:10.1111/j.16000560.2010.01607.x

24. Németh H1, Kovács E, Gödény S, Simics E, Pfliegler G. Autoimmune progesterone dermatitis diagnosed by intravaginal progesterone provocation in a hysterectomised woman. Gynecol Endocrino 2009;25(6):410-412. DOI:10.1080/09513590902770164

25. Wintzen M, Goor-van Egmond MB, Noz KC. Autoimmune progesterone dermatitis presenting with purpura and petechiae. Clin Exp Dermatol 2004;29(3):316. DOI:10.1111/j.1365-2230.2004.01516x

. Ebadi MS. Desk Reference of Clinical Pharmacology. Florida: CRC Press, 2008.

27. Sasseville D, Wilkinson RD, Schnader JY. Dermatoses of pregnancy. Int J Dermatol 1981;20(4):223241. DOI:10.1111/j.1365-4362.1981.tb04327.x

28. Cocuroccia B, Gisondi P, Gubinelli E, Girolomoni G. Autoimmune progesterone dermatitis. Gynecol Endocrinol 2006;22(1):54-56. DOI:10.1080/09513590500216735

29. Dedecker F, Graesslin O, Quereux C, Gabriel R, Salmon-Ehr V. Autoimmune progesterone dermatitis: A rare pathology. Eur J Obstet Gynecol Reprod Biol 2005;123(1):120-121. DOI:http://dx.doi org/10.1016/j.ejogrb.2005.03.007

30. Hill JL, Carr TF. Iatrogenic autoimmune progesterone dermatitis treated with a novel intramuscula progesterone desensitization protocol. J Allergy Clin Immunol Pract 2013;1 (5):537-538. DOI:10.1016/ jaip.2013.06.005

31. Teelucksingh S, Edwards CR. Autoimmune progesterone dermatitis. J Intern Med 1990;227(2):143 144. DOI:10.1111/j.1365-2796.1990.tb00133.x

Accepted 2 December 2015 